\title{
Peritoneal Carcinomatosis Present in Signet Ring Cells Gastric Carcinoma-Case Report
}

\author{
Ana Lazarova* and Antonio Gligorievski
}

Department of Radiology, Medical faculty, University Clinic for surgery disease St. Naum Ohridski, Macedonia

ISSN: 2637-7632

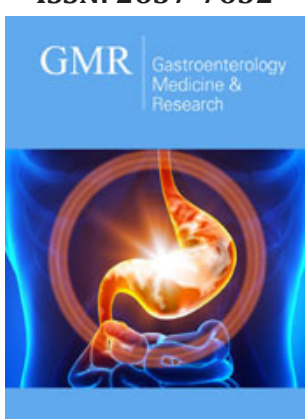

*Corresponding author: Ana Lazarova, Department of Radiology, St. Kiril and Methodius, Medical faculty, University Clinic for surgery disease St. Naum Ohridski, Macedonia

Submission: 㭗 November 23, 2020

Published: 眥December 10, 2020

Volume 5 - Issue 3

How to cite this article: Ana Lazarova, Antonio Gligorievski. Peritoneal Carcinomatosis Present in Signet Ring Cells Gastric Carcinoma-Case Report. Gastro Med Res. 5(3). GMR. 000612. 2020. DOI: $10.31031 /$ GMR.2020.05.000612

Copyright@ Ana Lazarova, This article is distributed under the terms of the Creative Commons Attribution 4.0 International License, which permits unrestricted use and redistribution provided that the original author and source are credited.

\begin{abstract}
Peritoneal carcinomatosis (PC) is an important and not rare cause of morbidity and mortality among patients with gastric cancer. Younger age(less than 65 years) female gender, advanced T- and N-stage, a primary tumor of signet ring cells or linitis plastica, and primary tumors covering multiple anatomical locations of the stomach were all associated with a higher odds ratios of developing PC. PC is a frequent condition in patients presenting with gastric cancer, especially in younger patients with advanced tumor stages. In this article, we present a case of a 63 years old woman who was operatively treated for gastric cancer. Total gastrectomy was obtained and the patohistology report was signet ring cell carcinoma, stage T3N3M0. Computer tomography (CT) was done before the operative treatment and 6 months after the treatment. The CT before the treatment did not show any presents of peritoneal metastasis, there were no signs of peritoneal involvement. The next CT was done 6 months after the treatment where there was a sign of peritoneal involvement, with the diffuse spread of metastatic deposits (MS) all over the peritoneum. The present study showed a positive correlation between a more advanced T-stage and $\mathrm{N}$-stage and the risk of presenting with PC. In literature, these factors were also associated with worse survival. This patient survival period was 4 months after diagnosis of peritoneal carcinomatosis with correlate with the data from the literature were median survival of patients with other metastases was 14 months, but only 4 months for patients with PC.
\end{abstract}

Conclusion: Over $70 \%$ of gastric cancer patients undergoing surgery with curative intent will develop intra-abdominal recurrence in the course of the disease. The spread of malignant cells into the peritoneal cavity during surgery is one of the possible mechanisms for this phenomenon. PC is a frequent condition in patients presenting with gastric cancer, especially in younger patients with advanced tumor stages.

\section{Introduction}

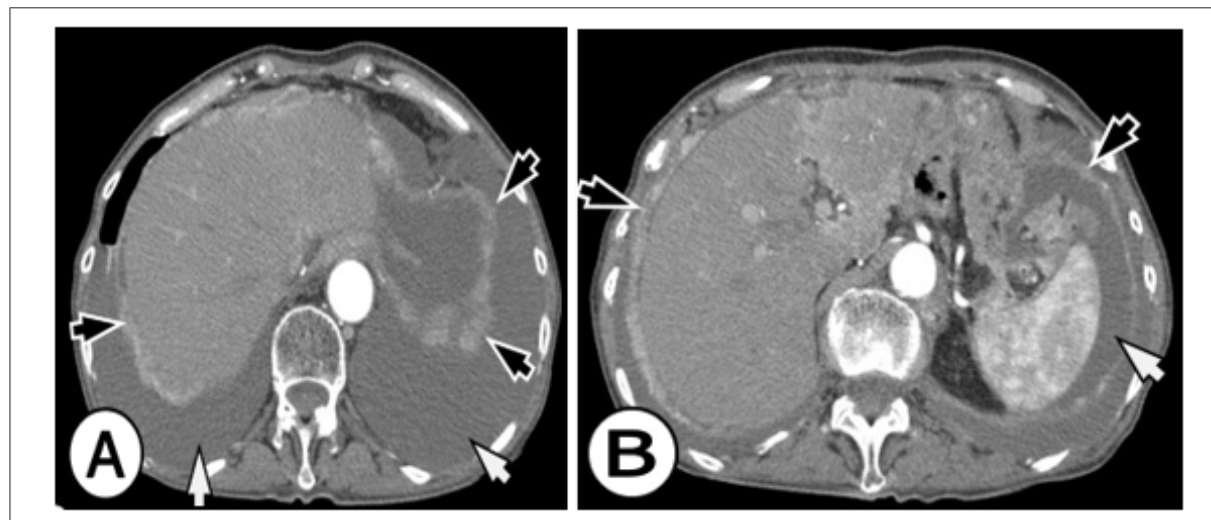

Figures 1A \& 1B: Peritoneal carcinomatosis from signet ring cell gastric carcinoma in a 63-year-old woman who complained of diffuse abdominal pain. Enhanced computed tomographic (CT) images in the level of the liver show a large amount of ascites (white arrows), nodular soft tissue thickening of the subdiaphragmatic peritoneum (black arrows).

Gastric cancer is present and also known for its aggressive behavior and is the second main cause of death from cancer worldwide accounting for 740,000 deaths per year [1,2]. Incidence rates of gastric cancer vary throughout the world, but with two-thirds occurring in 
developing countries [3]. Radical operation is the main treatment for gastric cancer, but the recurrence rate following surgery is high due to the early dissemination of cancer cells via the lymphatic system (about 40-80\%) in advanced gastric cancer [4,5]. Western surgical studies have shown that most patients present with tumors that penetrated the submucosa, they have a 5 -year survival rate of 20-30\% [6]. Postoperative chemotherapy is a standard treatment component of resectable gastric cancer and has improved patient outcomes (Figure 1). Treatment results of adjuvant chemotherapy may depend on the interaction between residual cancers and anticancer drugs [7-9]. Peritoneum and liver are the most common metastatic sites among patients with gastric cancer. Peritoneal carcinomatosis (PC) can lead to bowel obstruction and the formation of massive amounts of malignant ascites, therefore resulting in death. Although of its fatal consequences, the incidence of PC in gastric cancer is currently unknown $[10,11]$.

PC is an important and not rare cause of morbidity and mortality among patients with gastric cancer [12]. The median survival period of patients with liver metastasis is 14 months but it is only 4 months for patients with PC (Figure 2). PC is a frequent condition in patients presenting with gastric cancer, especially in younger patients with advanced tumor stages [13,14]. Younger age (less than 60 years) female gender, advanced T- and N-stage, a primary tumor of signet ring cells or linitis plastica, and primary tumors covering multiple anatomical locations of the stomach were all associated with a higher odds ratio of developing PC. PC is a frequent condition in patients presenting with gastric cancer, especially in younger patients with advanced tumor stages $[15,16]$.
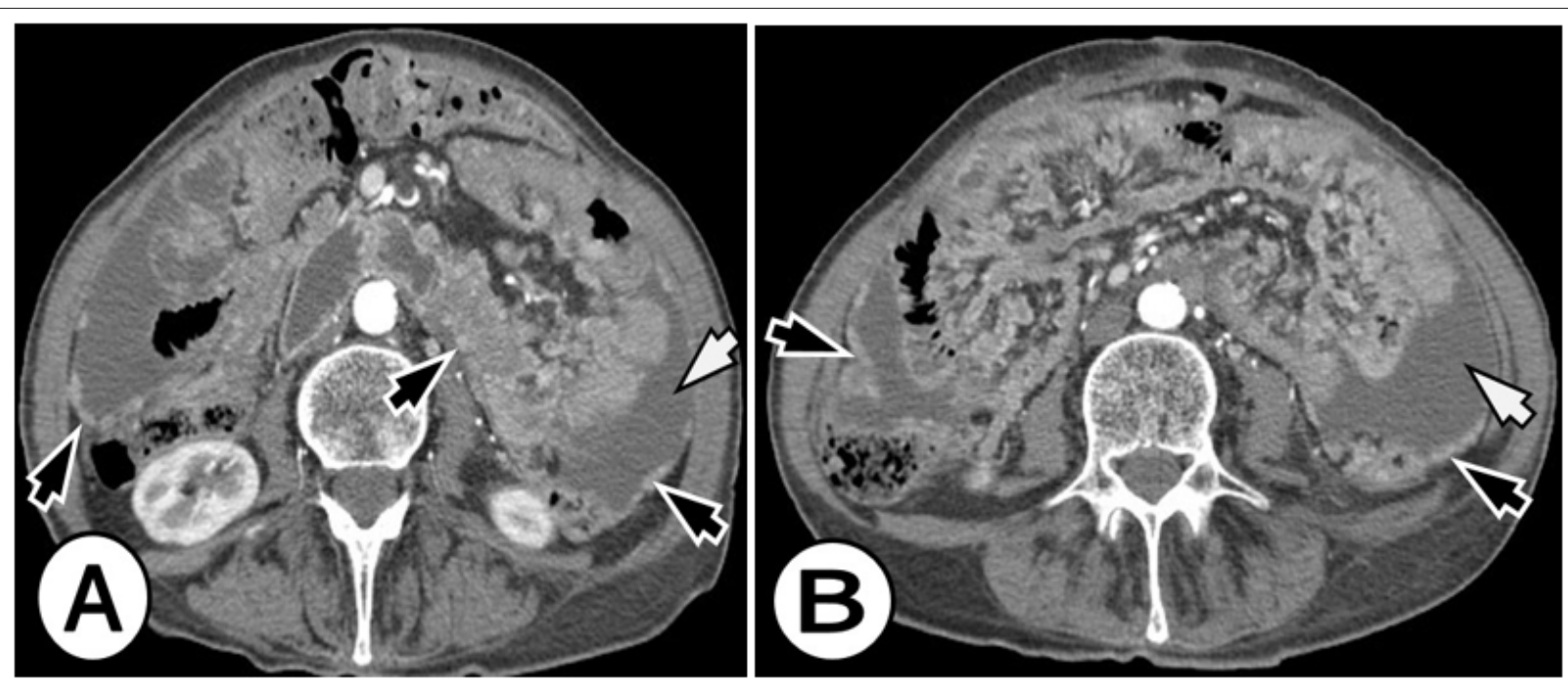

Figures 2A \& 2B: Peritoneal carcinomatosis from signet ring cell gastric carcinoma in a 63-year-old woman. Axial arterial phase CT images in the level of the kidneys, revealed multifocal nodules in the peritoneal cavity, peritoneal enhancement and thickening (black arrows), and ascites (white arrows).

\section{Case Report}
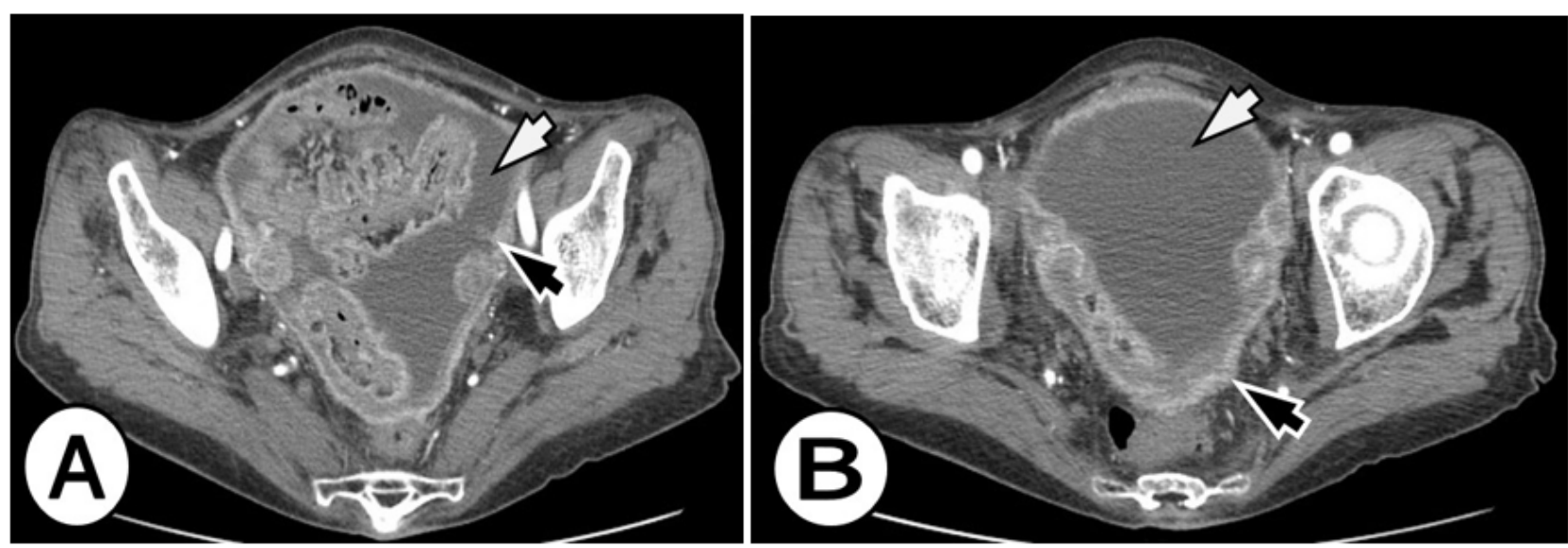

Figures 3A \& 3B: A 63-year-old woman with peritoneal carcinomatosis from signet ring cell gastric carcinoma.

Enhanced computed tomographic (CT) images in the level of pelvis show a large amount of ascites (white arrows), nodular soft tissue thickening of the peritoneum (black arrows). 
This is a case of 62 years old woman, who was previously diagnosed by gastroscopy with gastric cancer. Preoperatively computer tomography (CT) scan on the abdomen and lungs was done and no distant metastases were found. The patient was operatively treated and total gastrostomy as surgery procedure was obtained. Patohistology finding was signet ring cell carcinoma, stage T3N3M0. This patient went under the standard protocol of chemotherapy. Six mounts after the treatment follow-up CT scan was done, where diffuse dissemination of metastatic deposits (MS) all over the peritoneum was found and the diagnosis of peritoneal carcinomatosis was established also it was accompanied with free fluid in the abdomen and pelvis-ascites (Figure 3).

\section{Discussion}

It is proven that there is a positive correlation between a more advanced T-stage and N-stage and the risk of presenting with PC. In literature, these factors were also associated with worse survival [17]. This has been documented before in patients with colorectal cancer, which supports the hypothesis that PC is caused by serosal infiltration of the primary tumor and subsequent shedding of malignant cells into the peritoneal cavity [18]. Furthermore, patients with a primary signet ring cell or linitis plastica tumor had a higher risk of being diagnosed with synchronous PC as was recently also shown for the development of metachronous PC [19]. Identification of signet ring cell tumors may be important as this histological subtype has also been shown to have a negative prognostic impact on survival and has a poor response to chemotherapy [20,21]. The presence of PC had a profound negative impact on survival with a median survival of only 4 months [22]. In an attempt to treat advanced gastric cancer, different chemotherapeutic regimens have been investigated [23].

Cochrane review and meta-analysis demonstrated a convincing benefit for chemotherapy over best supportive care (three studies, n5184). In total, 35 trials with a total of 5,726 patients were included, which showed that combination chemotherapy, including 5-FU, anthracyclines, and cisplatin gave the best results compared to conventional chemotherapy [24]. Recently, the implementation of a multimodality treatment including aggressive cytoreductive surgery combined with heated intraperitoneal chemotherapy (HIPEC) has led to promising results in selected patients with peritoneal malignancies of various origins, including colonic and ovarian cancer, mesothelioma and pseudomyxoma peritonei [25].

\section{Conclusion}

Over $70 \%$ of gastric cancer patients undergoing surgery with curative intent will develop intra-abdominal recurrence in the course of the disease. The spread of malignant cells into the peritoneal cavity during surgery is one of the possible mechanisms for this phenomenon. Given the bad prognosis of peritoneal dissemination, a strategy aimed at the prevention of PC by aggressive local treatment of patients at risk seems a realistic approach. PC is a frequent condition in patients presenting with gastric cancer, especially in younger patients with advanced tumor stages. Given the detrimental influence of PC on survival, efforts should be undertaken to further explore the promising results that were obtained in preventing or treating this condition with multimodality strategies.

\section{References}

1. Crew KD, Neugut AI (2006) Epidemiology of gastric cancer. World J Gastroenterol 12(3): 354-362.

2. Sugarbaker PH, Yonemura Y (2000) Clinical pathway for the management of resectable gastric cancer with peritoneal seeding: best palliation with a ray of hope for a cure. Oncology 58(2): 96-107.

3. Gretschel S, Siegel R, Estevez-Schwarz L, Hünerbein M, Schneider U, et al. (2006) Surgical strategies for gastric cancer with synchronous peritoneal carcinomatosis. Br J Surg 93(12): 1530-1535.

4. Bonenkamp JJ, Sasako M, Hermans J, Van de Velde CJ (2001) Tumor load and surgical palliation in gastric cancer. Hepatogastroenterology 48(41): 1219-1221.

5. Hioki M, Gotohda N, Konishi M, Toshio N, Shinichiro T, et al. (2010) Predictive factors improving survival after gastrectomy in gastric cancer patients with peritoneal carcinomatosis. World J Surg 34(3): 555-562.

6. Yan TD, Black D, Sugarbaker PH, Jacqui Z, Yutaka Y, et al. (2007) A systematic review and meta-analysis of the randomized controlled trials on adjuvant intraperitoneal chemotherapy for respectable gastric cancer. Ann Surg Oncol 14(10): 2702-2713.

7. Wagner AD, Unverzagt S, Grothe W, Gerhard K, Axel G, et al. (2010) Chemotherapy for advanced gastric cancer. Cochrane Database Syst Rev 3: CD004064.

8. Gill RS, Al-Adra DP, Nagendran J, Sandy C, Xinzhe S, et al. (2011) Treatment of gastric cancer with peritoneal carcinomatosis by cytoreductive surgery and HIPEC: A systematic review of survival, mortality, and morbidity. J Surg Oncol 104(6): 692-698.

9. Rossi CR, Pilati P, Mocellin S, Mirto F, Carlo O, et al. (2003) Hyperthermic intraperitoneal intraoperative chemotherapy for peritoneal carcinomatosis arising from gastric adenocarcinoma. Suppl Tumori 2(5): S54-57.

10. Glehen O, Schreiber V, Cotte E, Sayag Beaujard A, Osinsky D, et al. (2004) Cytoreductive surgery and intraperitoneal chemo hyperthermia for peritoneal carcinomatosis arising from gastric cancer. Arch Surg 139(1): 20-26.

11. Yonemura Y, Fujimura T, Nishimura G, Falla R, Sawa T, et al. (1996) Effects of intraoperative chemo hyperthermia in patients with gastric cancer with peritoneal dissemination. Surgery 119(4): 437-444.

12. Schouten LJ, Hoppener P, Van den Brandt PA (1993) Completeness of cancer registration in Limburg, the Netherlands. Int J Epidemiol 22(3): 369-376.

13. Zu H, Wang F, Ma Y, Xue Y (2013) Stage-stratified analysis of prognostic significance of tumor size in patients with gastric cancer. PLoS One 8(1): e54502.

14. Lemmens VE, Klaver YL, Verwaal VJ, Harm J, Jan Willem W, et al. (2010) Predictors and survival of synchronous peritoneal carcinomatosis of colorectal origin: A population based study. Int J Cancer 128(11): 27172725 .

15. Ceelen WP, Bracke ME (2009) Peritoneal minimal residual disease in colorectal cancer: Mechanisms, prevention, and treatment. Lancet Oncol 10(1): $72-79$

16. Knorr C, Reingruber B, Meyer T, Hohenberger W, Stremmel C, et al (2004) Peritoneal carcinomatosis of colorectal cancer: Incidence, prognosis, and treatment modalities. Int J Colorectal Dis 19(3): 181-187. 
17. Sadeghi B, Arvieux C, Glehen O, Beaujard A, Rivoire M, et al. (2000) Peritoneal carcinomatosis from non-gynecologic malignancies: Results of the EVOCAPE 1 multicentric prospective study. Cancer 88(2): 358363.

18. Sugarbaker PH (1994) Intraperitoneal chemotherapy for treatment and prevention of peritoneal carcinomatosis and sarcomatosis. Dis Colon Rectum 37(2): S115-S122.

19. Honore C, Goere D, Messager M, Souadka A, Dumont F, et al. (2013) Risk factors of peritoneal recurrence in eso-gastric signet ring cell adenocarcinoma: Results of a multicenter retrospective study. Eur J Surg Oncol 39(3): 235-241.

20. Messager M, Lefevre JH, Pichot V, Souadka A, Piessen G, et al. (2011) The impact of perioperative chemotherapy on survival in patients with gastric signet ring cell adenocarcinoma: A multicenter comparative study. Ann Surg 254(5): 684-693.

21. Piessen G, Messager M, Leteurtre E (2009) Signet ring cell histology is an independent predictor of poor prognosis in gastric adenocarcinoma regardless of tumoral clinical presentation. Ann Surg 250(6): 878-887.
22. Yang D, Hendifar A, Lenz C, Kayo T, Felicitas L, et al. (2011) Survival of metastatic gastric cancer: Significance of age, sex and race/ethnicity. J Gastrointest Oncol 2(2): 77-84.

23. Thomassen I, Lemmens VE, Nienhuijs SW, Misha D, Yvonne L, et al. (2013) Incidence, prognosis, and possible treatment strategies of peritoneal carcinomatosis of pancreatic origin: A population-based study. Pancreas 42(1): 72-75.

24. Klaver YL, Lemmens VE, Creemers GJ, Rutten HJ, Nienhuijs SW, et al. (2011) Population-based survival of patients with peritoneal carcinomatosis from colorectal origin in the era of increasing use of palliative chemotherapy. Ann Oncol 22(10): 2250-2256.

25. Verwaal VJ, Bruin S, Boot H, Gooike S, Harm T, et al. (2008) 8-year follow up of randomized trial: Cytoreduction and hyperthermic intraperitoneal chemotherapy versus systemic chemotherapy in patients with peritoneal carcinomatosis of colorectal cancer. Ann Surg Oncol 15(9): 2426-2432. 